\title{
Effectiveness of Indacaterol-Glycopyrronium in preventing COPD exacerbations in comparison to Salmeterol-Fluticasone
}

\author{
Shamim Ahmed, Mohammed Atiqur Rahman, Shah Ashiqur Rahman Ashiq Choudhury
}

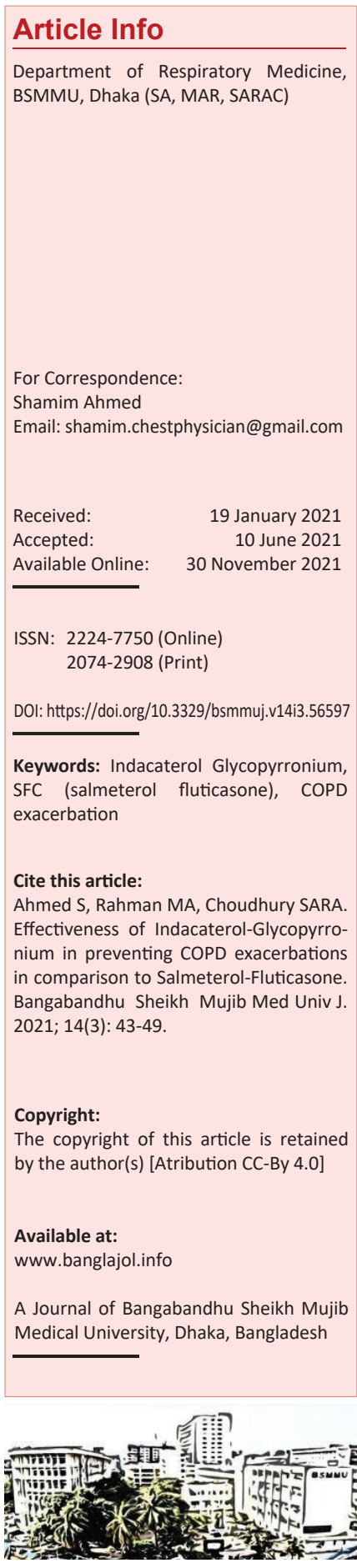

\begin{abstract}
COPD exacerbations are complex events usually associated with increased airway inflammation, increased mucus production and marked gas trapping. These changes contribute to increased dyspnoea that is the key symptom of an exacerbation. Inhaled long acting bronchodilators not only control symptoms but also prevent exacerbations of chronic obstructive pulmonary disease (COPD). The purpose of the study was to compare the efficacy between Indacaterol-Glycopyrronium and salmeterol fluticasone (SFC) in preventing COPD exacerbations during 24 weeks of treatment. This randomised active-controlled trial was conducted at Department of Respiratory Medicine, Bangabandhu Sheikh Mujib Medical University, Dhaka involving 200 patients with COPD exacerbations. Patients were randomly divided into two groups; \& treated with IndacaterolGlycopyrronium 110/50 ug o.d. \& Salmeterol-Fluticasone (50/500 ug b.i.d.) (SFC) respectively; \& follow-up was done after 12 and 24 weeks. The FEV1 was significantly higher at 12 and 24 weeks in the Indacateol- Glycopyrronium group compared with SFC. Statistically significant improvements in peak FVC was observed in IndacaterolGlycopyrronium when compared to SFC at week 12 and week 24 . Our study result showed that Indacaterol-Glycopyrronium was superior to Salmeterol-Fluticasone in terms of prevention and optimal management of COPD exacerbation.
\end{abstract}

\section{Introduction}

Chronic Obstructive Pulmonary Disease (COPD)

is a common, preventable and treatable disease that is characterized by persistent respiratory symptoms and airflow limitation that is due to airway and/or alveolar abnormalities usually caused by significant exposure to noxious particles or gases and influenced by host factors including abnormal lung development. ${ }^{1}$

Exacerbations of COPD are important events in the management of COPD because they negatively impact health status, rates of hospitalization and readmission, and disease progression. $^{2}$

COPD exacerbations are complex events usually associated with increased airway inflammation, increased mucus production and marked gas trapping. These changes contribute to increased dyspnoea that is the key symptom of an exacerbation. Other symptoms include increased sputum purulence and volume, together with increased cough and wheeze.

Chronic obstructive pulmonary disease (COPD) are associated with a rapid decline in lung function and it's associated with:

- Impaired quality of life $\mathrm{e}^{3}$

- Increased number of hospitalization ${ }^{4}$

- $\quad$ Increased mortality ${ }^{5}$

COPD exacerbations are costly to health care systems $^{6}$

Thus, prevention of exacerbations is a key goal in the management of COPD. ${ }^{7}$ Inhaled long acting bronchodilators not only control symptoms but also prevent COPD exacerbations. Inhaled glucocorticoids are also known to reduce the frequency of exacerbations and have been studied in combination with inhaled longacting betaagonists (LABAs). ${ }^{8,9,10}$ In one trial, the combination of a LABA plus an inhaled 
glucocorticoid (salmeterol-fluticasone) in fixed doses and the inhaled longacting muscarinic antagonist (LAMA) tiotropium had similar effects on the rate of COPD exacerbations among patients with a history of exacerbation. ${ }^{11}$

Consequently, treatment guidelines have recommended that either a LABA plus an inhaled glucocorticoid or a LAMA can be used to prevent COPD exacerbations in highrisk patients. ${ }^{12}$ Longterm use of glucocorticoids is associated with a small but important risk of pneumonia and other adverse effects. $^{13,14}$

An alternative to the combination of a LABA and an inhaled glucocorticoid for the prevention of COPD exacerbations in patients with a history of exacerbation is a dual bronchodilator regimen of a LABA and a LAMA. ${ }^{15}$

In the FLAME trial, it was investigated whether the LABA indacaterol $(110 \mu \mathrm{g})$ plus the LAMA glycopyrronium $(50 \mu \mathrm{g})$ once daily would be at least as effective as the LABA salmeterol $(50 \mu \mathrm{g})$ plus the inhaled glucocorticoid fluticasone $(500 \mu \mathrm{g})$ twice daily in preventing COPD exacerbations. ${ }^{16}$

Because recent studies have indicated that prevention of COPD exacerbations with inhaled glucocorticoids may be related to the blood eosinophil count, the relationship between the baseline blood eosinophil count and the rate of exacerbations associated with each intervention was examined prospectively. ${ }^{17-20}$

The 52week FLAME study confirmed superior efficacy of IND/GLY over SFC in terms of a reduced rate of all COPD exacerbations, improved through forced expiratory volume in 1 second (FEV1), improved quality of life, and a decrease in the use of rescue medication among patients who had a history of one or more exacerbation during the previous year. $^{21}$

The study was conducted with the purpose to compare the efficacy of between Indacaterol Glycopyrronium 110/50 ug o.d. and salmeterol fluticasone (50/500 ug b.i.d.) (SFC) in terms of rate of all COPD exacerbations during 24 weeks of treatment.

\section{Methods}

This randomised active-controlled trial was conducted at the department of Respiratory Medicine, BSMMU, Dhaka. A standardized questionnaire was formulated and slightly modified for convenient data collection. Data was collected in the questionnaire by face-to-face interviews of the participants.
Participants were selected after completing careful inquiries of inclusion and exclusion criteria. Finally, 200 respondents with a diagnosis of COPD (diagnosed on the basis of GOLD criteria $^{1}$ )with at least one exacerbation in the previous year were selected. Personal information including name, age, sex, religion, marital status, educational status, monthly income was covered. Detail of smoking history including pack-years was also documented. Information regarding COPD severity, duration, use of medication, history of hospitalization, ICS use at baseline were also taken.

The study population into two groups by simple random sampling. Each group had 100 participants. One group was given Indacaterol-Glycopyrronium, 110/50 microgram once daily and another group was given SulmeterolFluticasone, 50/500 microgram twice daily for 24 weeks as intervention.

Follow ups were done at baseline, 12 weeks and after 24 weeks. Spirometry was done at baseline, at 12 weeks and at 24 weeks. For FEV1, it was assumed that the estimated treatment difference between Indacaterol-Glycopyrronium and SFC was $0 \mathrm{~mL}$ and the non-inferiority margin was assumed to be $-60 \mathrm{~mL}$. This non inferiority margin was based on the treatment difference between SFC and placebo of $160 \mathrm{~mL}$ with a $95 \%$ confidence interval $(\mathrm{CI})$ of $120-200 \mathrm{~mL}^{16}$

During the procedure, each participant was monitored cautiously to find any potential adverse effect. Immediate measures were taken if there was any clinical or laboratory abnormality.

The study protocol was approved by The Institutional Review Board (IRB) of BSMMU. The detail of the study was explained to the participants and informed written consent was taken before data collection. Statistical analysis was done using the computer program SPSS (Statistical Package for the social science) version 23 .

\section{Results}

Patient demographics were comparable between treatment arms (Table - I). Most patients were male $(89 \%$ in Indacaterol-Glycopyrronium and $86 \%$ in SFC).

The majority of patients $(96 \%$ in IndacaterolGlycopyrronium and 91\% in SFC) in both treatment arms had moderate or severe COPD. (Figure-1) 37\% patients of Indacaterol-Glycopyrronium group and $29 \%$ patients of SFC group had a history of exacerbation in the past year. (Figure-2) 
Table-I

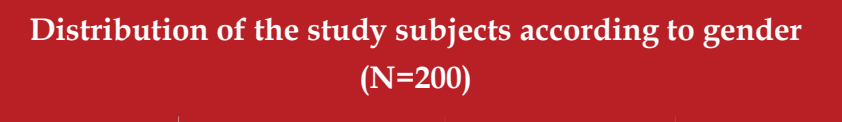

\begin{tabular}{|l|c|c|c|} 
Gender & $\begin{array}{c}\text { Indacaterol- } \\
\text { Glycopyrronium } \\
110 / 50 \mu \mathrm{g} \text { od } \\
\mathrm{n}=100\end{array}$ & $\begin{array}{c}\text { SFC } \\
50 / 500 \mu \mathrm{g} \text { bid } \\
(\mathrm{n}=100)\end{array}$ & p-value \\
\cline { 1 - 3 } Male & $89(68.9)$ & $86(73.0)$ & \multirow{2}{*}{0.277} \\
\cline { 1 - 3 } Female & $11(11 \%)$ & $14(14 \%)$ & \\
\cline { 1 - 3 } & &
\end{tabular}

Chi-squared test was done to compare between the groups. p-value $<.05$ was considered significant

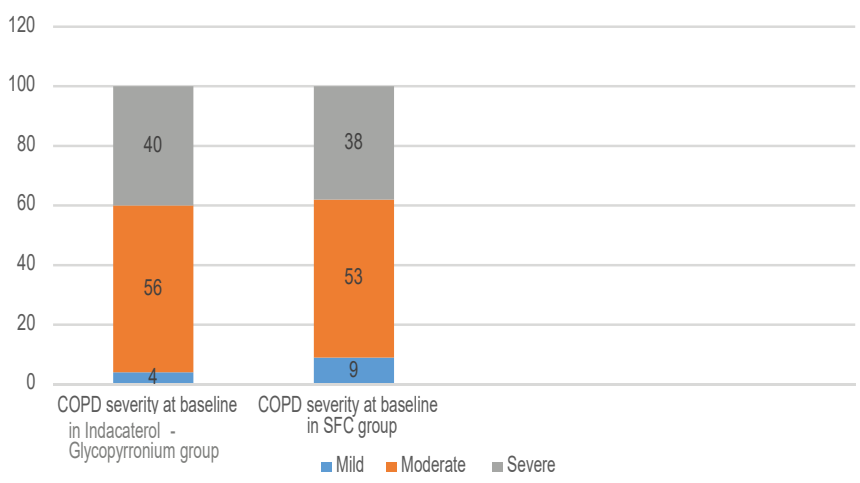

Figure - 1: Distribution of COPD patients according to severity at baseline in Indacaterol-Glycopyrronium and SFC groups

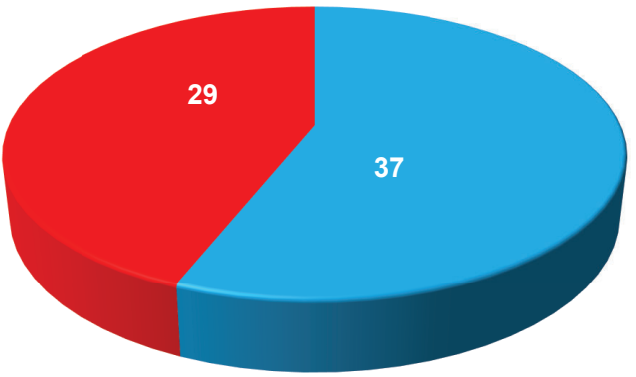

Figure - 2 : Distribution of patients according to history of COPD exacerbation in the past year between Indacaterol-Glycopyrronium and SFC groups

The mean post-bronchodilator $\%$ predicted $\mathrm{FEV}_{1}$ was approximately $52 \%$ in both groups. (Table-II)

When mMRC scores and lung function were assessed, $67 \%$ were classified as Gold B and 33\% classified as Gold D in Indacaterol-Glycopyrronium group and 58\% were classified as Gold B and 42\% classified as Gold D in SFC group. (Figure-3)
Table-II

Showing distribution of data according to the Post bronchodialator status at baseline.

\begin{tabular}{|l|c|c|}
\hline Traits & $\begin{array}{c}\text { Indacaterol- } \\
\text { Glycopyronnium } \\
110 / 50 \mu \mathrm{g} \text { od }\end{array}$ & $\begin{array}{c}\text { SFC } \\
50 / 500 \mu \mathrm{g} \text { bid }\end{array}$ \\
\hline Postbronchodilator FEV1, & $1.336(0.392)$ & $1.341(0.418)$ \\
\hline $\begin{array}{l}\text { Postbronchodilator FEV1, } \\
\% \text { predicted }\end{array}$ & $51.6(12.8)$ & $52.0(12.9)$ \\
\hline $\begin{array}{l}\text { Postbronchodilator FEV1 } \\
\text { reversibility, \% }\end{array}$ & $25.3(16.9)$ & $22.8(16.7)$ \\
\hline $\begin{array}{l}\text { Postbronchodilator } \\
\text { FEV1/FVC, \% }\end{array}$ & $42.7(9.9)$ & $43.0(10.0)$ \\
\hline
\end{tabular}

GOLD 2014 Classification

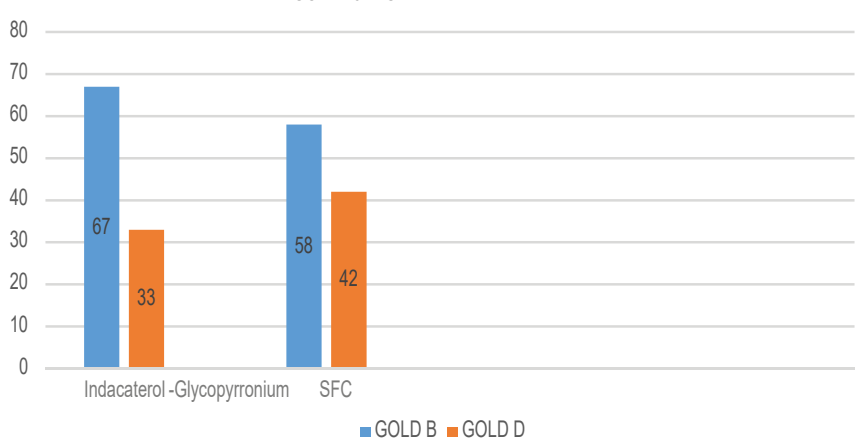

Figure - 3: Distribution of patients according to GOLD 2014 ABCD classification

\section{Spirometry}

At week 24, Indacaterol-Glycopyrronium was deemed to be non-inferior to SFC by meeting the predefined non-inferiority margin of $-60 \mathrm{~mL}$ in trough FEV1 (treatment difference [delta $=72 \mathrm{~mL} ; 95 \%$ CI:40, 104) for the per protocol set. Indacaterol-Glycopyrronium treatment demonstrated statistically significant superiority to SFC for trough FEV1 (delta $=75$ mL, 95\% CI: 44, 107; P<0.001; Figure - 3 \& Table - II) for the FAS. This significant improvement in trough FEV1 with Indacaterol-Glycopyrronium treatment compared with SFC was also observed at day 1 (delta $=43 \mathrm{~mL}, \mathrm{P}<0.001)$ and had reached a steady state by week 12 (delta $=78 \mathrm{~mL}$; $\mathrm{P}<0.001$; Table -III \& Table-IV).

Indacaterol-Glycopyrronium demonstrated statistically significant improvements in FEV1 at week 12 and week 24 when compared with SFC (delta $=65 \mathrm{~mL}$ and delta $=122 \mathrm{~mL}$, respectively; all P<0.001; Table-III \& Table -IV). The FEV1 was significantly higher at week 12 and week 24 in the Indacaterol-Glycopyrronium treatment arm compared 


\section{Table-III}

\section{Spirometry outcome after 12 weeks $(\mathrm{N}=\mathbf{2 0 0})$}

\begin{tabular}{|l|c|c|c|}
\hline Parameters & $\begin{array}{c}\text { Week } 12 \text { Indacaterol- } \\
\text { Glycopyrronium } 110 / 50 \mu \mathrm{g} \text { od }\end{array}$ & $\begin{array}{c}\text { SFC } \\
50 / 500 \mu \mathrm{g} \text { bid }\end{array}$ & $\begin{array}{c}\text { Treatment } \\
\text { difference }\end{array}$ \\
\hline FEV1, L & $1.28(0.016)$ & $1.21(0.016)$ & $0.078(0.046,0.111)^{* * *}$ \\
\hline FVC, L & $3.04(0.030)$ & $2.84(0.030)$ & $0.201(0.146,0.255)^{* * *}$ \\
\hline TDI focal score & $2.57(0.24)$ & $2.32(0.24)$ & $0.25(-0.09,0.59)$ \\
\hline $\begin{array}{l}\text { Change from baseline in mean } \\
\text { daily number of puffs }\end{array}$ & - & - & - \\
\hline $\begin{array}{l}\text { Percentage of days with no } \\
\text { rescue medication }\end{array}$ & - & - & - \\
\hline \begin{tabular}{l} 
CAT total score \\
\hline
\end{tabular} & $11.7(0.43)$ & $11.5(0.42)$ & $0.3(-0.4,0.9)$ \\
\hline
\end{tabular}

with SFC (all P<0.001; Table-III \& Table -IV). FVC was significantly higher for Indacaterol- Glycopyrronium than for SFC (P<0.001; Table-III \& Table-IV). Similarly, statistically significant improvements in peak FVC (taken over the first 4 hours) was observed in Indacaterol- Glycopyrronium when compared with SFC at week 12 and week 24 (all $\mathrm{P}<0.001$; Table-III \& Table -IV).

\section{Moderate or severe exacerbations}

In the overall patient population, the annualized rate of moderate or severe COPD exacerbations was significantly lower in the Indacaterol-Glycopyrronium treatment arm compared with $\mathrm{SFC}$ treatment arm $(\mathrm{P}=0.048)$, indicating a risk reduction of $31 \%$ (Table - V). Indacaterol-Glycopyrronium also significantly prolonged the time to first moderate or severe exacerbation and reduced the hazard of having such exacerbations by $35 \%$ when compared with SFC treatment $(\mathrm{P}=0.028)$

The incidence of serious AEs was lower in Indacaterol-Glycopyrronium - treated patients when compared to the SFC group. COPD was the major cause of serious AEs and was higher in the SFC treatment arm when compared to the Indacaterol-Glycopyrronium arm (Table-VI).

\section{Table-IV}

Spirometry outcome after 24 weeks $(\mathrm{N}=\mathbf{2 0 0})$

\begin{tabular}{|l|c|c|c|}
\hline \multirow{2}{*}{ Parameters } & \multicolumn{2}{|c}{$\begin{array}{c}\text { Week } 24 \\
\text { Indacaterol-Glycopyrronium SFC }\end{array}$} & \multirow{2}{*}{$\begin{array}{c}\text { Treatment } \\
\text { difference }\end{array}$} \\
\cline { 2 - 3 } & $110 / 50 \mu \mathrm{g} \mathrm{od}$ & $50 / 500 \mu \mathrm{g}$ bid & \\
\hline FEV1, L & $1.26(0.017)$ & $1.18(0.017)$ & $0.075(0.044,0.107)$ \\
\hline FVC, L & $2.97(0.033)$ & $2.79(0.033)$ & $0.173(0.115,0.231)$ \\
\hline TDI focal score & $2.91(0.27)$ & $-0.03(-0.26,0.21)$ & \\
\hline $\begin{array}{l}\text { Change from baseline in mean } \\
\text { daily number of puffs }\end{array}$ & $-1.51(0.129)-1.48(0.127)$ & $0.13(-0.20,0.47)$ \\
\hline $\begin{array}{l}\text { Percentage of days with no } \\
\text { rescue medication }\end{array}$ & $60.32(2.458) 59.36(2.418)$ & $0.96(-3.52,5.45)$ & \\
\hline CAT total score & $11.1(0.46)$ & $11.2(0.46)$ & \\
\hline
\end{tabular}




\begin{tabular}{|c|c|c|}
\hline \multicolumn{3}{|c|}{ Table-V } \\
\hline \multicolumn{3}{|c|}{ Summary and analysis of COPD exacerbations over 24 weeks by treatment group } \\
\hline \multirow[t]{2}{*}{ Parameters } & \multicolumn{2}{|c|}{ Moderate or severe COPD exacerbations } \\
\hline & $\begin{array}{l}\text { Indacaterol- } \\
\text { Glycopyrronium } \\
110 / 50 \mu \mathrm{g} \text { od }(\mathrm{n}=100)\end{array}$ & $\begin{array}{c}\text { SFC } 50 / 500 \mu \mathrm{g} \\
\quad \text { bid }(n=100)\end{array}$ \\
\hline \multicolumn{3}{|l|}{ Exacerbations per patient, $\mathrm{n}(\%)$} \\
\hline 0 & $88(88 \%)$ & $81(81 \%)$ \\
\hline 1 & $9(9 \%)$ & $14(14 \%)$ \\
\hline 2 & $2(2 \%)$ & $3(3 \%)$ \\
\hline 3 & 0 & 0 \\
\hline$>/=4$ & 0 & 0 \\
\hline Total number of exacerbations & 53 & 81 \\
\hline Total number of treatment years & 179.2 & 174.9 \\
\hline Rate of exacerbations per year & 0.30 & 0.46 \\
\hline $\begin{array}{l}\text { Treatment comparison versus SFC } \\
\text { ratio of rate }(95 \% \mathrm{CI})\end{array}$ & $0.69(0.48,1.00)$ & \\
\hline
\end{tabular}

\begin{tabular}{|l|c|c|}
\hline \multicolumn{3}{|c|}{ Table-VI } \\
\hline \multicolumn{2}{|c|}{ Number (\%) of AEs, SAEs, and deaths (safety set) } \\
\hline Parameters & $\begin{array}{c}\text { Indacaterol-Glyco } \\
\text { pyronnium } 110 / 50 \\
\mu g \text { od N=100 }\end{array}$ & $\begin{array}{c}\text { SFC } \\
\text { No } 500 \mu \mathrm{g} \text { bid } \\
\text { N } 100\end{array}$ \\
\hline any AE & $40(40 \%)$ & $47(47 \%)$ \\
\hline $\begin{array}{l}\text { any AEs in >/=1.5\% of } \\
\text { any group }\end{array}$ & & \\
\hline COPD worsening & $20(20 \%)$ & $26(26 \%)$ \\
\hline nasopharyngitis & $8(8 \%)$ & $12(12 \%)$ \\
\hline Upper respiratory tract infection & $3(3 \%)$ & $7(7 \%)$ \\
\hline Bronchitis & $7(7 \%)$ & $4(4 \%)$ \\
\hline Pneumonia & $3(3 \%)$ & $10(10 \%)$ \\
\hline Dyspnea & $1(1 \%)$ & $6(6 \%)$ \\
\hline Oropharyngeal pain & $1(1 \%)$ & $1(1 \%)$ \\
\hline AEs leading to discontinuation & $3(3 \%)$ & $5(5 \%)$ \\
\hline COPD worsening & $1(1 \%)$ & $2(2 \%)$ \\
\hline Any SAE & $5(5 \%)$ & $9(9 \%)$ \\
\hline COPD & $1(1 \%)$ & $4(4 \%)$ \\
\hline SAEs leading to discontinuation & $2(2 \%)$ & $3(3 \%)$ \\
\hline $\begin{array}{l}\text { non-SAE(s) leading to } \\
\text { discontinuation }\end{array}$ & $1(1 \%)$ & $2(2 \%)$ \\
\hline Deaths & $0(0 \%)$ & $0(0 \%)$ \\
\hline
\end{tabular}

\section{Discussion}

In this study, Indacaterol-Glycopyrronium once daily was compared with the LABA/ICS fixed-dose combination, SFC, administered twice daily in patients with moderate-to-severe COPD. The primary endpoint of this study was achieved, whereby Indacaterol- Glycopyrronium demonstrated non-inferiority by $\mathrm{FEV}_{1}$ when compared to SFC at week 24, and it also demonstrated superiority on this endpoint. In this study, $\mathrm{FEV}_{1}$ was considered as a primary endpoint to assess the bronchodilator effect. As SFC was administered twice daily, it was important to determine the bronchodilator effect after twice daily administration. Furthermore, improvement in $\mathrm{FEV}_{1}$ in all subgroups based on age, smoking history, COPD severity, ICS use at baseline, and exacerbations in the previous year was generally consistent with the overall study population.

Also, a statistically superior improvement in the key secondary endpoint, Peak FVC were observed with Indacaterol-Glycopyrronium treatment compared with SFC treatment. Thus, the study provides further evidence for the superiority of LABA/ LAMA combination therapy over LABA/ICS for improvement in lung function, as has been previously demonstrated by other studies. ${ }^{22}$ 
An important outcome of this study was the effect of Indacaterol-Glycopyrronium treatment on COPD moderate or severe exacerbations, when compared with LABA/ICS. Central to COPD management is the prevention of exacerbations. Previous studies have demonstrated the ability of LABA and LAMA mono therapies and LABA/ICS to reduce theexacerbation rates in COPD when compared to placebo.

In the INSPIRE (Investigating New Standards for Prophylaxis In Reducing Exacerbations) study ${ }^{12}$, LAMA monotherapy was comparable to LABA/ICS in terms of the rate of exacerbations experienced by COPD patients. In this study, patients receiving Indacaterol- Glycopyrronium had a significant reduction in moderate or severe exacerbations when compared to those receiving SFC.

This study confirmed the results of the ILLUMINATE study, while also building upon this data. A post hoc analysis of ILLUMINATE demonstrated that IndacaterolGlycopyrronium delayed the time to first exacerbation when compared with SFC in a population in which $19.8 \%$ of patients had severe COPD.

Significant improvements in lung function with Indacaterol-Glycopyrronium might be the reason for the reduction in the risk of exacerbations. It has been demonstrated in a Swedish study that IndacaterolGlycopyrronium is cost effective when compared with SFC, whereby the total estimated costs associated with the drug, maintenance, exacerbation, pneumonia, and costs were lower and resulted in better outcomes with IndacaterolGlycopyrronium when compared with SFC.

\section{Conclusion}

After all the results and discussions, we can draw a line mentioning the potential benefit of IndacaterolGlycopyrronium as an efficient tool of management of symptomatic COPD patients with history of previous exacerbation. Findings of this study indicate about the superiority of Indacaterol-Glycopyrronium regarding therapeutic benefit and safety issue over traditional SFC. This study may further contribute to the optimal management and prevention of COPD exacerbation.

\section{References}

1. Global Initiative for Chronic Obstructive Lung Disease (GOLD). Global Strategy for the Diagnosis, Management, and Prevention of Chronic Obstructive Pulmonary Disease. Available from: http://www. goldcopd.org/ uploads/users/files/ GOLD_Report_ 2015 _Feb18.pdf. Accessed March 14, 2015.
2. Wedzicha JA, Banerji D, Chapman KR, Vestbo J, Roche N, Ayers RT et al. Indacaterol-glycopyrronium versus salmeterol -fluticasone for COPD. New England Journal of Medicine. 2016 Jun 9;374(23):2222-34.

3. Vestbo J, Hurd SS, Agustí AG, Jones PW, Vogelmeier C, Anzueto A et al. Global strategy for the diagnosis, management, and prevention of COPD: GOLD executive summary. AJRCC. 2013 Feb 15;187(4):347-65.

4. Donaldson GC, Seemungal TA, Patel IS, Bhowmik A, Wilkinson TM, Hurst JR et al. Airway and systemic inflammation and decline in lung function in patients with COPD. Chest. 2005 Oct 1;128(4):1995-2004.

5. Müllerova H, Maselli DJ, Locantore N, Vestbo J, Hurst JR, Wedzicha JA et al. Hospitalized exacerbations of COPD: risk factors and outcomes in the ECLIPSE cohort. Chest. 2015 Apr 1;147(4):999-1007.

6. Soler-Cataluna JJ, Martinez-Garcia MA, Sánchez PR, Salcedo E, Navarro M, Ochando R. Severe acute exacerbations and mortality in patients with chronic obstructive pulmonary disease. Thorax. 2005 ;60(11):925-31.

7. Toy EL, Gallagher KF, Stanley EL, Swensen AR, Duh MS. The economic impact of exacerbations of chronic obstructive pulmonary disease and exacerbation definition: a review. COPD: Journal of Chronic Obstructive Pulmonary Disease. 2010 May 1;7(3):214-28.

8. Tashkin DP, Doherty DE, Kerwin E, Matiz-Bueno CE, Knorr B, Shekar T et al. Efficacy and safety characteristics of mometasone furoate/formoterol fumarate fixed-dose combination in subjects with moderate to very severe COPD: findings from pooled analysis of two randomized, 52-week placebo-controlled trials. International journal of chronic obstructive pulmonary disease. 2012;7:73.

9. Kerwin E, Hébert J, Gallagher N, Martin C, Overend T, Alagappan VK et al. Efficacy and safety of NVA237 versus placebo and tiotropium in patients with COPD: the GLOW2 study. European Respiratory Journal. 2012;40(5):1106-14.

10. Calverley PM, Anderson JA, Celli B, Ferguson GT, Jenkins C, Jones PW et al. Salmeterol and fluticasone propionate and survival in COPD. NEJM. 2007 ;356(8):775-89.

11. Wedzicha JA. Mechanisms of chronic obstructive pulmonary disease exacerbations. Annals of the American Thoracic Society. 2015 Nov;12(Supplement 2):S157-9.

12. Wedzicha JA, Calverley PM, Seemungal TA, Hagan G, Ansari Z, Stockley RA. The prevention of COPD exacerbations by salmeterol/fluticasone propionate or tiotropium bromide. AJRCCM 2008;177(1):19-26. 
13. Crim C, Calverley PM, Anderson JA, Celli B, Ferguson GT, Jenkins $C$ et al. Pneumonia risk in COPD patients receiving inhaled corticosteroids alone or in combination: TORCH study results. European Respiratory Journal. 2009; 34(3):641-7.

14. Calverley PM, Stockley RA, Seemungal TA, Hagan G, Willits LR, Riley JH et al. Investigating New Standards for Prophylaxis in Reduction of Exacerbations (INSPIRE) Investigators. Reported pneumonia in patients with COPD: findings from the INSPIRE study. Chest. 2011;139(3):505-12.

15. Price D, Yawn B, Brusselle G, Rossi A. Risk-to-benefit ratio of inhaled corticosteroids in patients with COPD. Primary Care Respiratory Journal. 2013 Mar;22(1):92-100.

16. Wedzicha JA, Decramer M, Ficker JH, Niewoehner DE, Sandström T, Taylor AF et al. Analysis of chronic obstructive pulmonary disease exacerbations with the dual bronchodilator INDACATEROLGLYCOPYRRONIUM compared with glycopyrronium and tiotropium (SPARK): a randomised, double-blind, parallel-group study. The lancet Respiratory medicine. $2013 ; 1(3): 199-209$.

17. Pascoe S, Locantore N, Dransfield MT, Barnes NC, Pavord ID. Blood eosinophil counts, exacerbations, and response to the addition of inhaled fluticasone furoate to vilanterol in patients with chronic obstructive pulmonary disease: a secondary analysis of data from two parallel randomised controlled trials. The lancet Respiratory medicine. 2015 Jun 1;3(6):435-42.

18. Siddiqui SH, Guasconi A, Vestbo J, Jones P, Agusti A, Paggiaro $\mathrm{P}$ et al. Blood eosinophils: a biomarker of response to extrafine beclomethasone/ formoterol in chronic obstructive pulmonary disease. American journal of respiratory and critical care medicine. 2015 Aug 15;192(4):523-5.

19. Pavord ID, Lettis S, Locantore N, Pascoe S, Jones PW, Wedzicha JA et al. Blood eosinophils and inhaled corticosteroid/long-acting $\beta$-2 agonist efficacy in COPD. Thorax. 2016 Feb 1;71(2):118-25.

20. De Torres JP, Pinto-Plata V, Ingenito E, Bagley P, Gray A, Berger $\mathrm{R}$ et al. Power of outcome measurements to detect clinically significant changes in pulmonary rehabilitation of patients with COPD. Chest. 2002 Apr 1;121(4):1092-8.

21. Skoupa J, Kasak V, Klimes J, Valena T. Indacaterol/ glycopyrronium versus salmeterol/fluticasone in patients with COPD - a cost-effectiveness analysis in the Czech Republic. Value in health regional issues. 2018 Sep 1;16:112-8.

22. Bateman ED, Ferguson GT, Barnes N, Gallagher N, Green $\mathrm{Y}$, Henley $\mathrm{M}$ et al. Dual bronchodilation with INDACATEROL-GLYCOPYRRONIUM versus single bronchodilator therapy: the SHINE study. European Respiratory Journal. 2013 Dec 1;42(6):1484-94. 